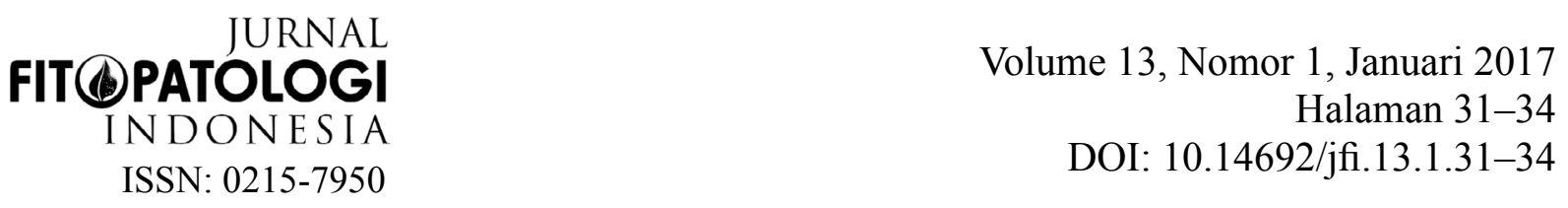

TEMUAN PENYAKIT BARU

\title{
Penyakit Karat Bawang Daun yang Disebabkan oleh Puccinia allii Rud.
}

\author{
Rust Disease on Bunching Onion Caused by Puccinia allii Rud. \\ Widodo $^{1 *}$, Ginting Tri Pamungkas ${ }^{2}$, Hendry Susetyo $^{2}$, Antoni Setiawan ${ }^{2}$, Johanis Wowor ${ }^{3}$ \\ ${ }^{1}$ Institut Pertanian Bogor, Bogor 16680 \\ ${ }^{2}$ Direktorat Perlindungan Tanaman Hortikultura, Jakarta Selatan 12520 \\ ${ }^{3}$ Balai Proteksi Tanaman Pangan dan Hortikultura Propinsi Sulawesi Utara, Manado 95112
}

\begin{abstract}
ABSTRAK
Penyakit baru pada bawang daun (Allium fistulosum) dengan gejala khas sebagai penyakit karat ditemukan di Kecamatan Tompaso Barat dan Kecamatan Modoinding, Kabupaten Minahasa Selatan pada bulan Juni 2016. Tanaman yang terinfeksi di lapangan menunjukkan gejala berupa pustulpustul berwarna cokelat kekuningan pada permukaan daun. Daun yang terserang menampakkan gejala menguning lalu mengering yang dimulai dari bagian pucuk. Insidensi penyakit di lokasi survei mencapai $100 \%$ dengan tingkat keparahan penyakit 30\%-50\%. Berdasarkan pengamatan mikroskopis pada karakter morfologi cendawan yang ditemukan, yaitu uredium dan urediniospora, penyakit tersebut disebabkan oleh Puccinia allii Rud.
\end{abstract}

Kata kunci: Allium fistulosum, insidensi penyakit, pustul cokelat, urediniospora

\begin{abstract}
New disease of bunching onion (Allium fistulosum) with typical symptoms as rust disease was found in the sub-district of West Tompaso and Modoinding, District of South Minahasa, North Sulawesi in June 2016. Infected plants in the field showed yellowish brown pustules on leaf surface, followed by leaf yellowing and drying out started from the tip. Disease incidence in surveyed area reached $100 \%$ with disease severity between $30 \%-50 \%$. Based on microscopic observation of the fungal morphological characteristic, i.e. uredium dan urediniospora, the causal agent was identified as Puccinia allii Rud.
\end{abstract}

Key words: Allium fistulosum, brown pustule, disease incidence, urediniospora

Pada tanggal 19 Juli 2016 Klinik Tanaman Departemen Proteksi Tanaman Fakultas Pertanian, Institut Pertanian Bogor menerima laporan tentang kerusakan tanaman pada bawang daun dengan gejala berupa bintikbintik cokelat kekuningan dan daun yang terserang parah mengering dari Kabupaten Minahasa Selatan, Sulawesi Utara. Pada awal Agustus 2016 Direktorat Perlindungan Tanaman Hortikultura, Kementerian Pertanian Republik Indonesia mengundang Klinik Tanaman IPB untuk melakukan survei lapangan di Kecamatan Tompaso Barat (Desa Sinisir), dan Kecamatan Modoinding (Desa Makaruyan, Desa Kakenturan, dan Desa Linelean), Kabupaten Minahasa Selatan.

*Alamat penulis korespondensi: Departemen Proteksi Tanaman, Fakultas Pertanian, Institut Pertanian Bogor. Jalan Kamper Kampus IPB, Darmaga, Bogor 16680.

Telp: 0251-8629364, Faks: 0251-862362, surel: widodo@apps.ipb.ac.id 
Berdasarkan pada ciri-ciri gejala yang sangat khas diduga adanya penyakit karat daun pada bawang daun. Pada pengamatan di lapangan terlihat adanya gejala penguningan daun yang merata di lahan (Gambar 1a) dan daun mengering (Gambar 1b) serta ditemukan adanya pustul-pustul berwarna cokelat kekuningan (Gambar 1c). Pengamatan secara mikroskopis menggunakan handheld digital microscope (Dino-Lite AM 2111 Basic, AnMo Electronic Co. Taiwan) terlihat secara jelas pustul-pustul tersebut adalah uredinium berisi urediniospora (Gambar 1d). Konfirmasi dari irisan tipis menunjukkan adanya uredinium (Gambar 1e) dengan urediniospora berwarna cokelat kekuningan di dalamnya (Gambar 1f).

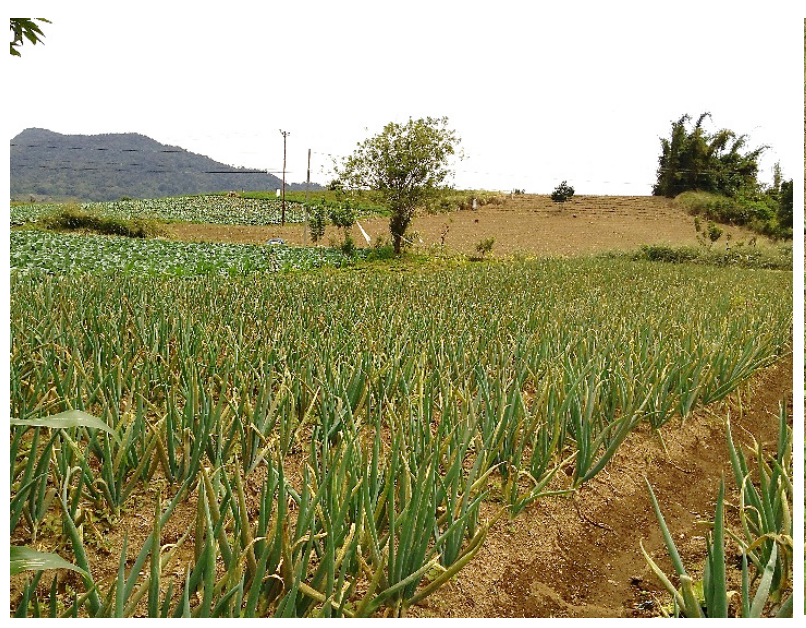

a

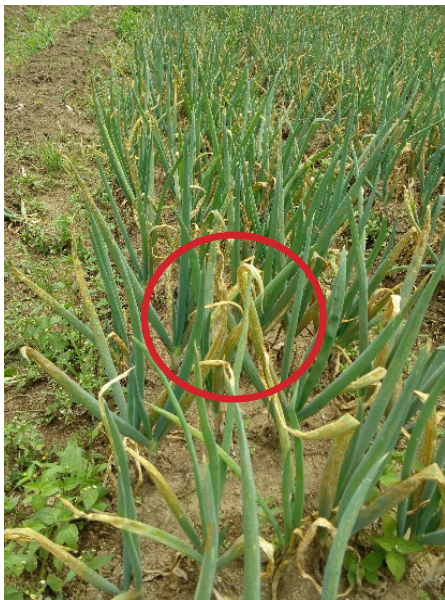

b

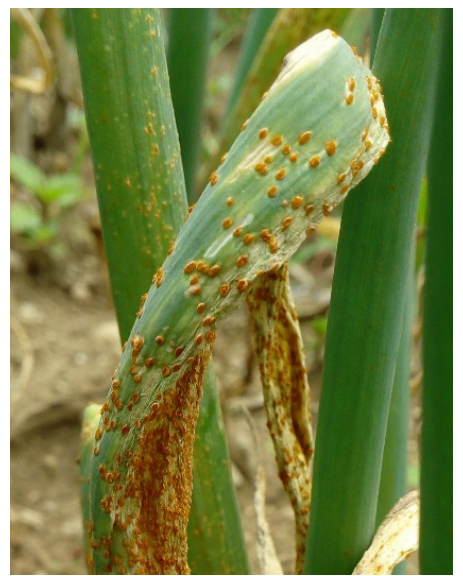

$\mathrm{c}$

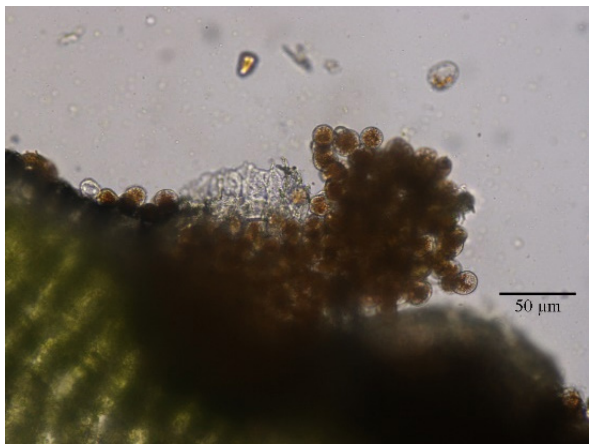

e

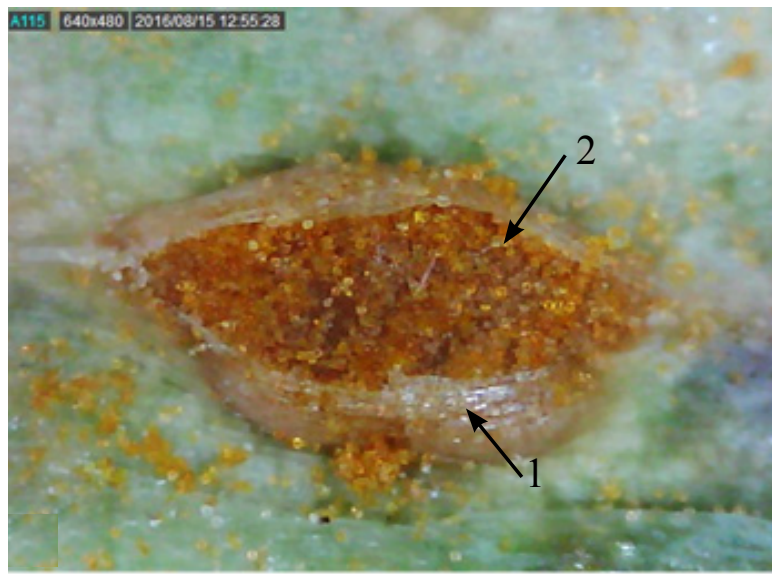

d

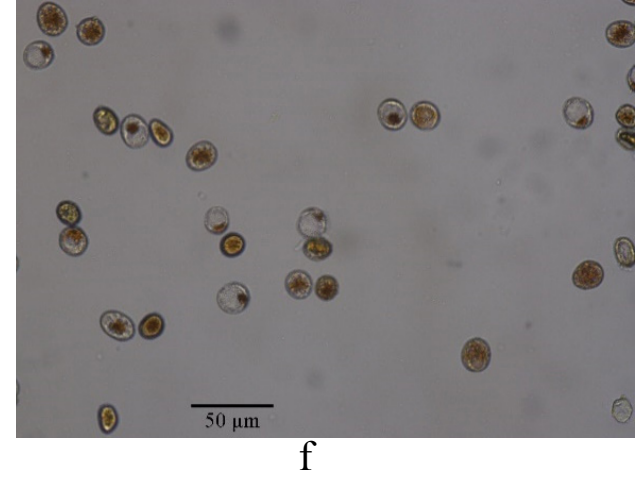

Gambar 1 Gejala penyakit dan tanda patogen karat pada bawang daun. a, gejala serangan pada tajuk tanaman di lapangan; $b$, gejala pucuk daun menguning dan mengering (tanda lingkaran); c, uredinium patogen berupa pustul pada permukaan daun; d, uredinium (1) dan urediniospora (2); e, uredinium berisi urediniospora pada jaringan daun dan; f, urediniospora. 
Urediniospora berbentuk membulat sampai jorong dengan ukuran $11.96-17.93 \times 10.03$ $-13.98 \mu \mathrm{m}$.

Jika dilihat dari uredinium yang tidak dikelilingi asesori (parafisis) (Gambar 1e) dan ornamentasi permukaan sporanya berupa duri yang lembut (ekilunet) (Gambar 1f) maka berdasarkan kunci identifikasi Hiratsuka dan Sato (1982) cendawan karat yang ditemukan menyerang bawang daun ini termasuk genus Puccinia. Menurut Henderson (2004) spesies yang menyerang bawang daun (Allium fistulosum) dan spesies Allium yang lain adalah Puccinia allii Rud. Selain $P$. allii juga dilaporkan spesies cendawan karat lainnya, yaitu Uromyces durus yang diketahui terdapat pada A. nipponicum (Ito 1923). Sebaran inang dari spesies tersebut hanya diketahui menyerang tanaman genus Allium. Menurut Pusat Karantina Pertanian (1988) penyakit karat ini kadang-kadang ditemukan pada pertanaman bawang putih di Sumatera, Jawa dan Bali, tetapi sejauh ini belum ada publikasi ilmiah resmi di Indonesia yang menunjukkan hal tersebut. Sejauh pengamatan yang telah dilakukan oleh Klinik Tanaman Departemen Proteksi Tanaman, IPB penyakit tersebut belum pernah ditemukan di lapangan sebelumnya. Sementara itu menurut petani di Kabupaten Minahasa Selatan keberadaan penyakit karat ini pada bawang daun baru dialami pada tahun 2016. Berdasarkan data EPPO Global Database (2011) distribusi penyakit tersebut belum ada di Indonesia, tetapi negara terdekat yang telah melaporkan penyakit ini ialah Filipina. Penyakit ini akan berkembang secara optimum jika kelembapan udara sekitar $97 \%$ dan kisaran suhu $10-15{ }^{\circ} \mathrm{C}$ (Hill 1995). Kondisi lingkungan ini sangat memungkinkan terjadi di daerah survei yang ketinggiannya antara 1080-1100 m dari permukaan laut ketika suhu udaranya sesuai bagi perkembangan penyakit tersebut.

Dari contoh lahan di empat desa yang diamati, insidensi penyakit mencapai 100\% dan keparahan penyakit berkisar 30\%-50\%. Insidensi yang tinggi ini sangat mungkin terjadi, karena urediniospora $P$. allii sangat mudah dipencarkan oleh angin (Hill 1995). Beberapa petani di tempat survei yang telah melakukan pengendalian dengan fungisida berbahan aktif campuran difenokonazol dan azoxistrobin menunjukkan tingkat keparahannya rendah (Gambar 2). Meskipun bahan aktif fungisida tersebut saat ini efektif mengendalikan, tetapi pemantauan secara rutin kemungkinan

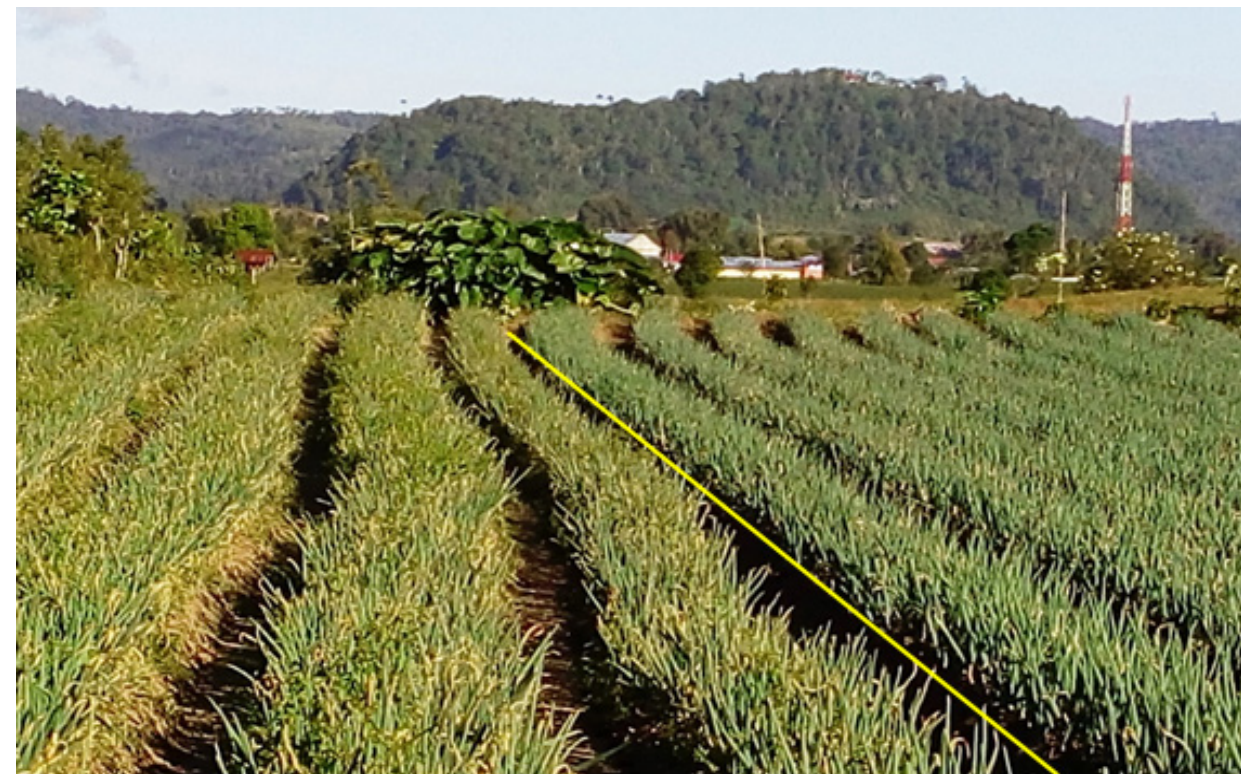

Gambar 2 Tingkat serangan P. allii pada pertanaman bawang daun yang tidak dan yang diaplikasi fungisida berbahan aktif campuran azoxistrobin dan difenokonazol. Tingkat serangan tinggi, (sebelah kiri garis kuning, tanpa apilikasi fungisida) dan rendah (sebelah kanan garis kuning, diaplikasi fungisida). 
munculnya resistansi patogen terhadap fungisida tersebut tetap diperlukan. Beberapa laporan penelitian menunjukkan adanya risiko resistansi bahan aktif tersebut terhadap patogen karat (Scherm et al. 2009; Oliver 2014).

\section{UCAPAN TERIMA KASIH}

Penulis mengucapkan terima kasih kepada Direktorat Perlindungan Tanaman Hortikultura, Kementerian Pertanian Republik Indonesia atas prakarsa dan pembiayaan survei ini.

\section{DAFTAR PUSTAKA}

EPPO Global Database. 2011. World distribution of Puccinia allii (PUCCAL). (https://gd.eppo.int/taxon/PUCCAL/ distribution). [diunduh 30 Agu 2016].

Henderson DM. 2004. The Rust of Fungi of British Isles: A Guide to Identification by Their Host Plants. Kew-Surrey (UK): British Mycolocical Society.

Hill JP. 1995. Rust. Di dalam: Schwartz HF, Mohan SK, editor. Compendium of Onion and Garlic Disease. St Paul-Minnesota (US): APS Pr. Hlm 24-25.

Hiratsuka Y, Sato S. 1982. Morphology and taxonomy of rust fungi. Di dalam: Scott K, Chakravorty AK, editor. The Rust Fungi. New York (US): Academic Pr. Hlm 1-36.

Ito S. 1923. Uromyces of Japan. J Coll Agric Hokkaido Imp Univ. 11(4):211-287.

Oliver RP. 2014. Reassessment of the risk of rust fungi developing resistance to fungicides. Pest Manag Sci. 70:16411645. DOI: https://doi.org/10.1002/ ps.3767.

Pusat Karantina Pertanian. 1988. Daftar Organisme Pengganggu Tanaman Penting yang Dilaporkan Telah Terdapat di Dalam Wilayah Republik Indonesia. Jakarta (ID): Pusat Karantina Pertanian.

Scherm H, Christiano RSC, Esker PD, Del Ponte EM, Godoy CV. 2009. Quantitative review of fungicides efficacy trials for managing soybean rust in Brazil. Crop Prot 28:774-782. DOI: https://doi. org/10.1016/j.cropro.2009.05.006. 